\title{
Results of high heat flux testing of W/CuCrZr multilayer composites with percolating microstructure for plasma-facing components
}

\author{
Henri Greuner, Alessandro Zivelonghi, Bernd Böswirth, Jeong-Ha You \\ Max Planck Institute for Plasma Physics, Boltzmannstr. 2, D-85748 Garching, Germany
}

Reliable joining of tungsten to copper is a major issue in the design of water-cooled divertor components for future fusion reactors. One of the suggested advanced engineering solutions is to use functionally graded composite interlayers.

Recently, the authors have developed a novel processing route for fabricating multi-layer graded W/CuCrZr composites. Previous characterization confirmed that the composite materials possess enhanced strength compared to the matrix alloy and shows reasonable ductility up to $300{ }^{\circ} \mathrm{C}$ indicating large potential to extend the operation temperature limit. Furthermore, a three-layer composite system (W volume fraction: 70/50/30\%) was developed as a graded interlayer between the $\mathrm{W}$ armor and CuCrZr heat sink.

In this study, we investigated the structural performance of the graded joint. Three water-cooled mock-ups of a flat tile type component were fabricated using electron beam welding and thermally loaded at the hydrogen neutral beam test facility GLADIS. Cycling tests at $10 \mathrm{MW} / \mathrm{m}^{2}$ and screening tests up to $20 \mathrm{MW} / \mathrm{m}^{2}$ were successfully performed and confirmed the expected thermal performance of the compound. The measured temperature values were in good agreement with the prediction of finite element analysis. Microscopic investigation confirmed the structural integrity of the newly developed functionally graded composite after these tests.

Keywords: Divertor, Tungsten/ Copper composite, plasma-facing component, high heat flux

\section{Introduction}

The divertor for future fusion reactors must allow steady-state operation under heat flux loads of at least 10 $\mathrm{MW} / \mathrm{m}^{2}$ and a limited number of slow thermal transients up to $15 \mathrm{MW} / \mathrm{m}^{2}$ or higher. The current design of the water-cooled divertor for the DEMO reactor is based on an extrapolation of the ITER divertor design according to the European roadmap for fusion power [1] and the EU Power Plant Conceptual Study (PPCS) [2]. Tungsten as plasma-facing material bonded onto $\mathrm{Cu}$ based heat sinks is the basic design concept of the water-cooled divertor. A design concern is the large mismatch in the coefficients of thermal expansion (CTE) at $300{ }^{\circ} \mathrm{C}$ between $\mathrm{W}\left(4.6 \times 10^{-6} \mathrm{~K}^{-1}\right)$ and $\mathrm{Cu}\left(17.6 \times 10^{-6} \mathrm{~K}^{-1}\right)$ which is likely to produce high stresses during high heat flux (HHF) loading. Thus, the performance of the target component relies on the quality of the joining and reduction of mismatch stress between $\mathrm{W}$ armor and $\mathrm{Cu}$ heat sink.

One of the possible engineering approaches is to use a functionally graded composite interlayer at the bond interface in order to mitigate the CTE mismatch and thus to reduce thermal stresses. Powder metallurgically sintered $\mathrm{W} / \mathrm{Cu}$ composites have been commercially available for decades [3]. However, the joining technology for the manufacturing of reliable plasmafacing component (PFCs) is still immature.

As a new solution, the application of $\mathrm{W} / \mathrm{CuCrZr}$ composites increases the strength at elevated temperatures compared to a pure $\mathrm{Cu}$ matrix and extends the operation temperature of the PFCs. A novel processing route for fabricating graded $\mathrm{W} / \mathrm{CuCrZr}$ composites using a vacuum melt infiltration method was developed in close cooperation with the Dresden University of Technology, Institute of Materials Science, the Fraunhofer Institute for Manufacturing and Advanced Materials (Dresden) and the Max-PlanckInstitute for Plasma Physics. Previous characterization showed that the composite materials possess enhanced strength compared to the matrix alloy but still maintaining excellent thermal conductivity and acceptable ductility [4-6]. A computational study was performed to understand the deformation and fracture behavior of the composite on the basis of its microstructure [7]. All these results indicate the potential of these functionally graded composites (FGCs) to be applied to the DEMO divertor, in particular, in terms of operating temperature range.

In this study, we investigated the structural performance of a FGC-reinforced target component system under HHF fatigue loads. To this end, we fabricated three water-cooled mock-ups of a flat tile type consisting of W armour, FGC interlayer and $\mathrm{Cu}$ alloy heat sink bonded using electron beam welding (see Sec.2). HHF fatigue tests were carried out at the neutral beam hydrogen beam test facility GLADIS [8]. The first results of the HHF fatigue tests are presented in section 4 . The focus of the investigation was placed on the thermal and mechanical performance of the FGC mock-ups under DEMOrelevant steady-state heat loads. Section 5 discusses the microstructural integrity of the FGC interlayer including the bond interfaces. These issues are discussed on the basis of thermal diagnostic data, microscopic damage analysis and nonlinear finite element analysis (FEA) simulations. 


\section{Mock-up manufacturing}

\subsection{Manufacture of graded composites}

For the production of a porous graded $\mathrm{W}$ skeleton with three layers, mixed powders were pressed layer by layer and then sintered. In the second step, CuCrZr material was placed on top of the sintered $\mathrm{W}$ and heated to $1200^{\circ} \mathrm{C}$ for $30 \mathrm{~min}$. The molten CuCrZr flowed into the pores of the $\mathrm{W}$ skeleton and formed W/CuCrZrcomposites. A continuous infiltration process was applied to fabricate a three-layer W/CuCrZr FGC laminate system (W volume fraction: 70/50/30\%) in a single process. A $2 \mathrm{~mm} \mathrm{CuCrZr}$ layer remained on the bottom side of the highly porous W skeleton. Finally the $\mathrm{CuCrZr}$ in the skeleton was precipitation hardened. The thermal conductivity $\lambda$ of the three layers was calculated from thermal diffusivity data measured by a laser flash device (Netsch LFA427) in the temperature range from $20-600^{\circ} \mathrm{C}$. The measured values (unit $\mathrm{Wm}^{-1} \mathrm{~K}^{-1}$ ) at $20^{\circ} \mathrm{C}$ are; $\lambda=310$ for the W30 layer with 70 vol\% CuCrZr, $\lambda=250$ for the W50 layer and $\lambda=230$ for the W70 layer [5]. Further details of the synthesis and the thermo-mechanical properties of these $\mathrm{W} / \mathrm{CuCrZr}$ composites are published in references $[4,5]$. The thicknesses and the compositions of the FGC interlayer were determined by a microstructure-based simulation study of their thermal- and mechanical behavior [6]. This novel technique allowed one to achieve uniform and good quality joining at the bond interfaces resulting from the mutually percolating microstructure of the two phases.

\subsection{Manufacture of the component}

One of the manufactured flat tile mock-ups is shown in Fig.1. The overall dimensions are $140 \times 27 \times 35 \mathrm{~mm}^{3}$. The cooling channel of the CuCrZr heat sink has a $12 \mathrm{~mm}$ diameter. The bonding of the $12 \times 9 \times 5.5 \mathrm{~mm}^{3} \mathrm{~W}$ tiles onto the $\mathrm{W} / \mathrm{CuCrZr}$ composite was performed during the $\mathrm{CuCrZr}$ infiltration process. This method was used, as the direct bonding of the $\mathrm{W}$ tiles during the sintering process was not successfully. As an improvement of such type of PFCs, a direct bonding of $\mathrm{W}$ tiles to the $\mathrm{W} / \mathrm{CuCrZr}$ composite would increase the thermal performance significantly. Each of the $4.3 \mathrm{~mm}$ thick $\mathrm{W} / \mathrm{CuCrZr}$ composites is covered with four $\mathrm{W}$ tiles. To join the $\mathrm{W} / \mathrm{CuCrZr}$ composite to the CuCrZr cooling structure, the above mentioned CuCrZr layer was electron beam welded onto the heat sinks. Two holes for thermocouples (TC) are located centrally between the cooling channel and the electron beam welding; $3.5 \mathrm{~mm}$ below the $\mathrm{W} / \mathrm{CuCrZr}$ composites.

\section{High heat flux loading}

HHF tests were carried out on three mock-ups in the HHF test facility GLADIS at IPP Garching. The loading parameters are measured with an accuracy of $\pm 5 \%$. The applied cooling conditions (water velocity $12 \mathrm{~m} / \mathrm{s}$, inlet temperature $15{ }^{\circ} \mathrm{C}$ and static pressure $1 \mathrm{MPa}$ ) ensure safe heat transfer in the regime of sub-cooled boiling up to $20 \mathrm{MW} / \mathrm{m}^{2}$ heat flux and resulted in a

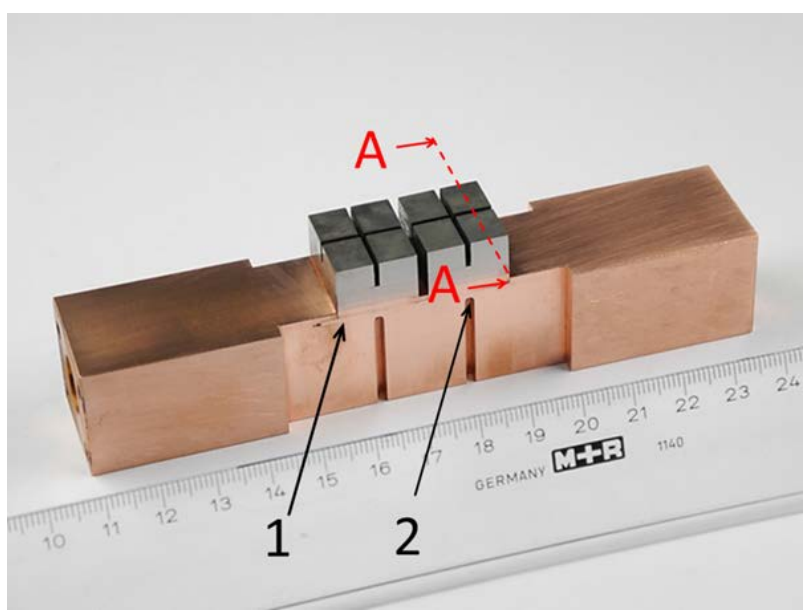

Fig. 1. Mock-up with a W/CuCrZr multilayer composite. Four $\mathrm{W}$ tiles are bonded on each individual multilayer composite. The electron beam welding between composite and cooling structure is marked (1), (2) shows the position of the TCs and the dashed line A-A marks the position of the micrographs shown in section 4 .

maximum inner cooling wall temperature of $\sim 240^{\circ} \mathrm{C}$ for $10.5 \mathrm{MW} / \mathrm{m}^{2}$ and $\sim 290^{\circ} \mathrm{C}$ for $15 \mathrm{MW} / \mathrm{m}^{2}$ loading, respectively. Despite the low cooling water temperature, the resulting wall temperatures are comparable with the expected maximum inner wall temperature of $298{ }^{\circ} \mathrm{C}$ from the PPCS Model A reference design [2].The central surface temperature of the exposed mock-ups was measured with one- and two-colour pyrometers as well as monitored by an infrared camera Infratec VARIOCAM HD. The two-colour pyrometer $(\varnothing 6 \mathrm{~mm}$ focus, $\lambda=1.4-1.75 \mu \mathrm{m}$, temperature range $500-1700{ }^{\circ} \mathrm{C}$ [9]) was used as reference for the emissivity determination of the one-colour pyrometer $(\varnothing 8 \mathrm{~mm}$ focus, $\lambda=1 \mu \mathrm{m}$, temperature range $650-2200^{\circ} \mathrm{C}$ ) [10] and the IR camera. The approach of adjusting the one-colour pyrometer to the data acquired with the two-colour pyrometer relies fully on the correctness of the temperatures measured by two-colour pyrometry. This is, however, only fully correct for a so-called "grey body", where the emissivity is assumed to be independent of wavelength and temperature. To estimate the error margin we used emissivity $(\varepsilon)$ data from reference [11] measured on $\mathrm{W}$ at $1200-1972 \mathrm{~K}$ surface temperature. For the two central wavelengths of the employed two-colour pyrometer the variation of the emissivity is about $5 \%$. We applied $\varepsilon=0.2-0.4$ for the one-colour pyrometer and $\varepsilon=0.07-0.11$ for the IR camera on the basis of the two-colour pyrometer results. A variation of $\varepsilon$ was necessary in the course of the experiments due to $\mathrm{W}$ surface conditioning (cleaning) during heat loading. This was presumably caused by the changing surface morphology during the HHF loading. The temperature of the cooling structure was measured by type-K TCs at two positions.

\section{Results of HHF loading}

The summary of the currently performed HHF loading is shown in Table 1 . Additional cycling tests at $230^{\circ} \mathrm{C}$ 
water inlet temperature and 4MPa are foreseen after an improvement of the GLADIS water cooling system in 2015.

\begin{tabular}{|l|c|c|c|c|}
\hline & $\begin{array}{c}\text { Heat } \\
\text { flux } \\
\text { MW/m² }\end{array}$ & Cycles & $\begin{array}{c}\text { Pulse } \\
\text { length } \\
\text { s }\end{array}$ & $\begin{array}{c}\text { Surface } \\
\text { temp. } \\
{ }^{\circ} \mathbf{C}\end{array}$ \\
\hline Mock-up 1 & $1-10.5$ & 18 & 20 & - \\
& 10.5 & 10 & 20 & 1360 \\
& 13 & 2 & 20 & 1659 \\
& 15 & 2 & 20 & 1916 \\
& 20 & 3 & $2-10$ & 2502 \\
\hline Mock-up 2 & $1-10.5$ & 19 & 20 & - \\
& 10.5 & 104 & 15 & 1310 \\
& 13 & 2 & 20 & 1607 \\
& 15 & 10 & 20 & 1902 \\
\hline Mock-up 3 & $1-10.5$ & 19 & 20 & - \\
& 10.5 & 2 & 20 & 1322 \\
& 13 & 60 & 20 & 1602 \\
& 15 & 50 & 20 & 1857 \\
\hline
\end{tabular}

Table 1. Summary of the performed HHF tests.

Mock-up 1 was only used for a screening test up to the thermal limit of $20 \mathrm{MW} / \mathrm{m}^{2}$. We detected a W tile with insufficient bonding during the first heat pulse at 1 $\mathrm{MW} / \mathrm{m}^{2}$. The tile was removed before $4.5 \mathrm{MW} / \mathrm{m}^{2}$ heat loading. A second bonding failure occurred during the $15 \mathrm{MW} / \mathrm{m}^{2}$ loading. Nevertheless, the mock-up survived the loading without further damage. At $20 \mathrm{MW} / \mathrm{m}^{2}$, the $\mathrm{Cu}$ layer between one $\mathrm{W}$ tile and the $\mathrm{W} / \mathrm{CuCrZr}$ composite melted after $10 \mathrm{~s}$ loading as predicted from the FEA calculation. The undamaged part of this mockup was cut and microscopically investigated.

Mock-up 2 was successfully cycled at $10 \mathrm{MW} / \mathrm{m}^{2}$ and further tested with low cycle numbers up to $15 \mathrm{MW} / \mathrm{m}^{2}$ without any indication of damage or overheating as shown in Fig. 2.

Mock-up 3 was successfully cycled at higher heat fluxes with higher cycle numbers. We did not detect any damage after $15 \mathrm{MW} / \mathrm{m}^{2}$ cycling. The surface temperature distribution, observed by IR and CCD camera was homogenous at the end of loading.

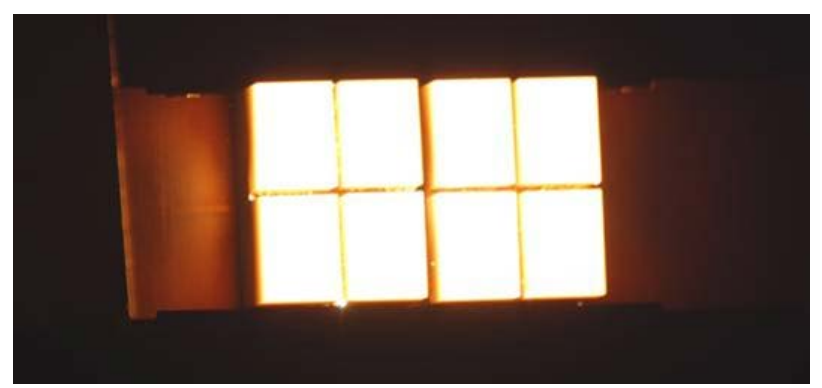

Fig. 2: Image of mock-up 2 at the end of the last $15 \mathrm{MW} / \mathrm{m}^{2}$ pulse.

The temperature evolution with increasing heat load is shown in Fig. 3 for all mock-ups. The predicted and

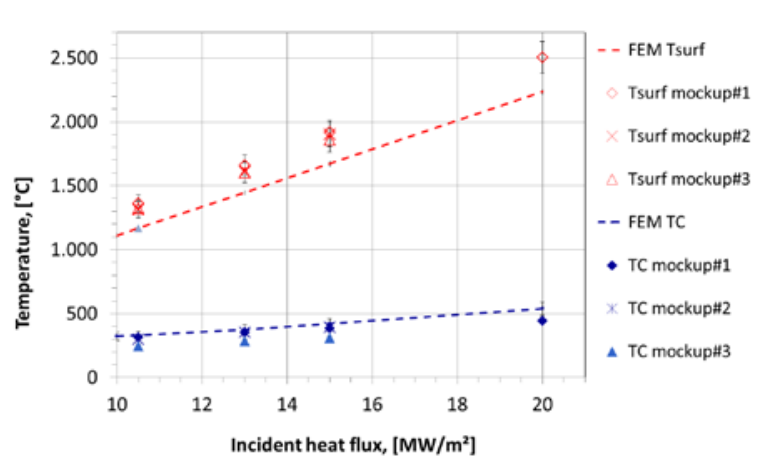

Fig. 3: Comparison of predicted and measured temperatures during HHF loading. The shown measured temperatures are average values for each loading step.

measured cooling structure temperatures are in good agreement. The quality of bonding of the TCs into the cooling structure may cause the small differences of the measured temperatures. In the case of the about $10 \%$ higher measured surface temperatures we assume an additional thermal resistance due to the electron beam welding and a slightly higher thermal resistivity of the composite. The expected temperature distribution in the cross-section of the mock-up was calculated for $10-20$ $\mathrm{MW} / \mathrm{m}^{2}$ heat flux. Fig. 4 shows as an example of the FEM temperature distribution for the $15 \mathrm{MW} / \mathrm{m}^{2}$ loading case. The applied material properties of the $\mathrm{W} / \mathrm{CuCrZr}$ composites are given in reference [5].

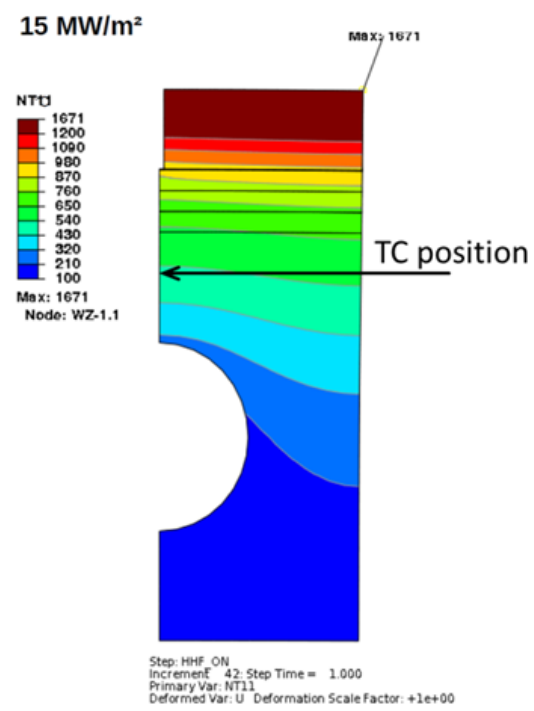

Fig. 4: FEM calculated temperature distribution for $15 \mathrm{MW} / \mathrm{m}^{2}$. The three layers of the W/CuCrZr composites are marked by solid gray lines.

\section{Microscopic investigation}

Optical microscopy investigations were performed on the metallographic cross-section (marked in Fig.1) of mock-up 1 after the HHF test. We observed a relatively high porosity of the electron beam weld with sporadic 
pores of up to $0.4 \mathrm{~mm}$ in diameter. This could be a reason for the higher surface temperatures mentioned in section 4. The two investigated $\mathrm{W}$ tiles show small fissures close to the W/CuCrZr composite. It seems that the cracks had already occurred during the manufacturing since both are filled with $\mathrm{Cu}$ and we did not measure a higher surface temperature at this position. Fig. 5 presents the most important part of the mock-ups, the three layer W/CuCrZr composite. This composite is completely free of cracks and shows a homogenous distribution of CuCrZr inside the $\mathrm{W}$ skeleton. The bonding to the CuCrZr layer is without damage. This finding is supported by the visual inspection of the other mock-ups after heat loading. We did not see any cracks or delaminations in the W/CuCrZr composite of both the mock-ups.

The microstructure of the investigated $\mathrm{W}$ tiles is characterised by fine grains with partial grain growth up to $\sim 2.5 \mathrm{~mm}$ below the loaded surface as shown in Fig. 6 . According to the FEM predictions we expected local $\mathrm{W}$ temperatures of $>1700^{\circ}$ during the $15 \mathrm{MW} / \mathrm{m}^{2}$ loading and $>2200^{\circ} \mathrm{C}$ during the $20 \mathrm{MW} / \mathrm{m}^{2}$ loading, respectively, in this region. However, no surface cracks were identified.

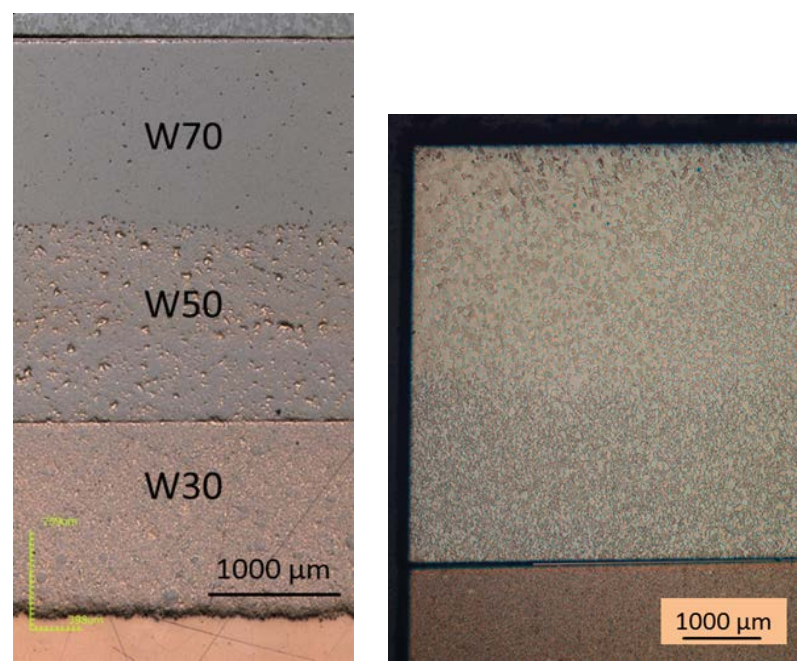

Fig. 5 (left hand): Cross section of the W/CuCrZr composite after heat loading up to $20 \mathrm{MW} / \mathrm{m}^{2}$. The lower part of the image shows the CuCrZr layer. The pure $\mathrm{W}$ plasma-facing material is visible on the top.

Fig.6 (right hand): $\mathrm{W}$ tile as plasma facing material on the top of the W/CuCrZr composite. A slight grain growth of the upper part of the $\mathrm{W}$ tile is visible

\section{Discussion and conclusions}

A tri-layered W/CuCrZr composite (W70, W50, W30\%vol) with a mutually percolating dual-phase microstructure was developed to mitigate the mismatch of thermal expansion of $\mathrm{W}$ and the CuCrZr heat sink in a PFC mock-up. As a new solution, the development of infiltrated W/CuCrZr composites increases the strength at elevated temperatures compared to a pure $\mathrm{Cu}$ matrix and extends the operating temperature of water-cooled divertor targets. The HHF performance of water-cooled divertor mock-ups equipped with a newly developed three layers $\mathrm{W} / \mathrm{CuCrZr}$ composite was experimentally investigated up to $20 \mathrm{MW} / \mathrm{m}^{2}$.

The thermal behaviour during the heat flux loading is in good agreement with the FEM predicted temperatures. Furthermore, microscopic investigations confirmed that the implementation of the novel functionally graded interlayer was successful. We did not detect any defect in the $\mathrm{W} / \mathrm{CuCrZr}$ composite after heat loading up to 20 $\mathrm{MW} / \mathrm{m}^{2}$. Additional cycling tests at $230^{\circ} \mathrm{C}$ water inlet temperature and $4 \mathrm{MPa}$ are foreseen after an upgrade of the GLADIS water cooling system in 2015.

As a proof of principle, the feasibility of such $\mathrm{W} / \mathrm{CuCrZr}$ composites as an efficient graded interlayer material for water-cooled divertor targets was demonstrated in the present HHF tests. The manufacturing technology was successfully developed for $\mathrm{W}$ flat tile bonding, however, it could also be applicable for the bonding of $\mathrm{W}$ monoblocks to CuCrZr tubes. As a further improvement of such type of FGC, a direct bonding of $\mathrm{W}$ tiles to the $\mathrm{W} / \mathrm{CuCrZr}$ composite is considered.

\section{Acknowledgments}

This work has been carried out within the framework of the EUROfusion Consortium and has received funding from the European Union's Horizon 2020 research and innovation programme under grant agreement number 633053. It was partly funded by Deutsche Forschungsgemeinschaft.

\section{References}

[1] F. Romanelli, Fusion Electricity - A roadmap to the realisation of fusion energy, European Fusion Development Agreement 2012, ISBN 978-3-00-040720-8

[2] D. Maisonnier, I. Cook, P. Sardain, R. Andreani, L. Di Pace, R. Forrest et al., Final Report of the European Power Plant Conceptual Study, 2005, EFDA-RP-RE-50, available online http://www.efdfa.org.

[3] R. Kiefer, W. Hotop, Pulvermetallurgie und Sinterwerkstoffe, Springer Verlag Berlin, 2nd ed., 1948

[4] S. Nawka, T. Schubert, A. Brendel, A. Zivelonghi, J.-H. You and B. Kieback, Proc. Powder Metallurgy World Congr.(2010) Vol.5 pp 383-90

[5] J.-H. You, A. Brendel, S. Nawka, T. Schubert and B. Kieback, Journal of Nuclear Materials 438 (2013) 1-6

[6] A. Zivelonghi, A. Brendel, S. Lindig, S. Nawka, B. Kieback and J.-H. You, Journal of Nuclear Materials 417 (2011) 536-539

[7] A.Zivelonghi and J.-H. You, Computational Materials Science 84 (2014) 318-326

[8] H. Greuner, B. Boeswirth, J. Boscary and P. McNeely, Journal of Nuclear Materials. 367-370 (2007) 1444

[9] Dr. Georg Maurer GmbH, Kohlberg, type QKTR 1075-1

[10] Dr. Georg Maurer GmbH, Kohlberg, type KTR 1085

[11] Y. S. Touloukian, D.P. DeWitt, 1970 Thermophys. Prop. of Matter 7796 